\title{
Multislice computed tomography assessment of everolimus-eluting Absorb bioresorbable scaffolds in comparison with metallic drug-eluting stents from the ABSORB Japan randomised trial
}

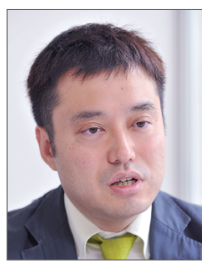

Kengo Tanabe ${ }^{1 *}$, MD; Jeffrey J. Popma², MD; Ken Kozuma³ ${ }^{3}$ MD; Shigeru Saito ${ }^{4}$, MD; Toshiya Muramatsu ${ }^{5}$, MD; Sunao Nakamura ${ }^{6}$, MD; Atsuo Namiki ${ }^{7}, \mathrm{MD}$; Yoshihiro Morino ${ }^{8}, \mathrm{MD}$; Nobuhisa Hagiwara $^{9}$, MD; Masaaki Uematsu ${ }^{10}$, MD; Tomohiro Kawasaki ${ }^{11}$, MD; Kenshi Fujii ${ }^{12}$, MD; Patrick W. Serruys ${ }^{13}$, MD; Yoshinobu Onuma ${ }^{13}$, MD; Shihwa Ying ${ }^{14}$, MS; Hajime Kusano ${ }^{14}$, PhD; Gregg W. Stone ${ }^{15}$, MD; Takeshi Kimura ${ }^{16}$, MD; on behalf of the ABSORB Japan Investigators

1. Mitsui Memorial Hospital, Tokyo, Japan; 2. Beth Israel Deaconess Medical Center, Boston, MA, USA; 3. Teikyo University Hospital, Tokyo, Japan; 4. Shonan Kamakura General Hospital, Kanagawa, Japan; 5. Tokyo General Hospital, Tokyo, Japan; 6. Shin-Tokyo Hospital, Chiba, Japan; 7. Kanto Rosai Hospital, Kanagawa, Japan; 8. Iwate Medical University Hospital, Iwate, Japan; 9. Tokyo Women's Medical University Hospital, Tokyo, Japan; 10. Kansai Rosai Hospital, Hyogo, Japan; 11. Shinkoga Hospital, Fukuoka, Japan; 12. Sakurabashi Watanabe Hospital, Osaka, Japan; 13. Thoraxcenter, Erasmus MC, Rotterdam, the Netherlands; 14. Abbott Vascular, Santa Clara, CA, USA; 15. Columbia University Medical Center, New York-Presbyterian Hospital, and the Cardiovascular Research Foundation, New York, NY, USA; 16. Kyoto University Graduate School of Medicine, Department of Cardiovascular Medicine, Kyoto, Japan

GUEST EDITOR: Daniele Andreini, MD, PhD, FESC, FSCCT; Cardiovascular CT Unit, Centro Cardiologico Monzino, IRCCS, Milan, and Department of Clinical Sciences and Community Health, Cardiovascular Section, University of Milan, Milan, Italy

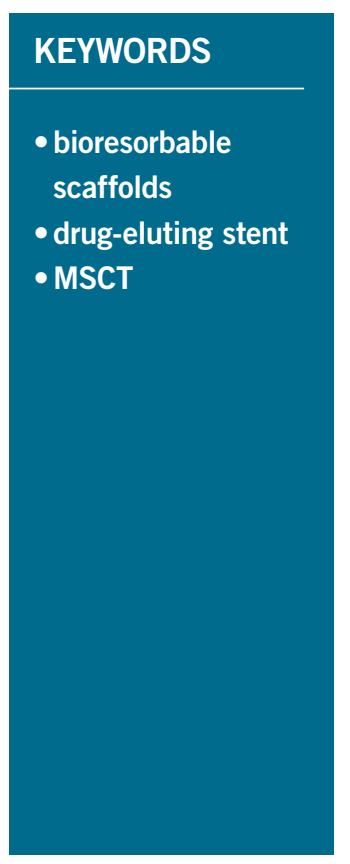

\begin{abstract}
Aims: Blooming artefacts limit accurate coronary assessment by multislice computed tomography (MSCT) in metallic stents. We sought to investigate whether bioresorbable vascular scaffolds (BVS) could be better assessed by MSCT.

Methods and results: Among 400 patients in the randomised ABSORB Japan trial, a pre-specified MSCT substudy was performed in 98 patients (103 lesions) in the BVS arm and 49 patients (49 lesions) in the cobalt-chromium everolimus-eluting stent (CoCr-EES) arm at 13 months prior to follow-up angiography. The assessability of BVS by MSCT was superior to that of CoCr-EES ( $94 \%$ versus $67 \%, \mathrm{p}<0.001)$. Blooming artefacts were the main reason CoCr-EES could not be analysed (29\%), while marker artefacts precluded analysis in $1.1 \%$ of BVS. In the CoCr-EES arm, non-assessable lesions were more prevalent in segments with $2.5 \mathrm{~mm}$ stents compared to 3.0 or $3.5 \mathrm{~mm}$ stents $(75.0 \%$ versus $23.5 \%$, p=0.01), while in the BVS arm image quality was good regardless of the diameter. The in-device minimal lumen diameter by MSCT was smaller than that by QCA with a difference of $0.61 \mathrm{~mm}$ in the CoCr-EES arm, vs. only $0.026 \mathrm{~mm}$ in the BVS arm.
\end{abstract}

Conclusions: The feasibility of MSCT assessment of BVS-treated lesions was greater than that for lesions with CoCr-EES.

\footnotetext{
*Corresponding author: Division of Cardiology, Mitsui Memorial Hospital, 1, Kanda-Izumicho, Chiyoda-ku, Tokyo, 101-8643, Japan.E-mail: kengo-t@zd5.so-net.ne.jp
} 


\begin{tabular}{ll}
\multicolumn{2}{l}{ Abbreviations } \\
BVS & bioresorbable vascular scaffold(s) \\
CoCr-EES & cobalt-chromium everolimus-eluting stent(s) \\
ID-TLR & ischaemia-driven target lesion revascularisation \\
MLD & minimal lumen diameter \\
MSCT & multislice computed tomography \\
QCA & quantitative coronary angiography \\
TIMI & Thrombolysis In Myocardial Infarction \\
TLF & target lesion failure \\
TV-MI & target vessel myocardial infarction
\end{tabular}

\section{Introduction}

Non-invasive assessment of coronary stenosis by multislice computed tomography (MSCT) has been clinically applicable for de novo lesions. However, the diagnostic accuracy in stented segments has been affected by blooming artefacts caused by the metallic stent struts. The assessablity of stenosis after coronary metallic stent implantation by MSCT ranges from $52 \%$ to $92 \%^{1-3}$. The recently developed everolimus-eluting bioresorbable vascular scaffold (BVS) is composed of a radiolucent poly-lactide backbone that does not induce blooming artefacts. One of the possible advantages of BVS over a metallic stent is the feasibility of MSCT assessment of coronary stenosis as an alternative to invasive coronary angiography during follow-up. Some previous studies have demonstrated that BVS did not preclude either qualitative or quantitative analysis by $\mathrm{MSCT}^{4,5}$. The presence of platinum markers on scaffold edges, however, may cause artefacts. There have been no previous prospective studies to compare the diagnostic accuracy of MSCT in BVS-treated segments with that in metallic stent-treated segments. Therefore, we sought to assess the diagnostic capability of MSCT in BVS as compared with metallic cobalt-chromium everolimus-eluting stents (CoCr-EES) in a prospective pre-specified MSCT substudy of the ABSORB Japan trial ${ }^{6}$.

\section{Methods}

\section{STUDY DESIGN}

The ABSORB Japan trial was a prospective, multicentre, randomised, single-blinded trial in which 400 patients were randomised in a 2:1 ratio to treatment with the Absorb ${ }^{\text {TM }}$ BVS (Abbott Vascular, Santa Clara, CA, USA) or a CoCr-EES (XIENCE PRIME $^{\circledR} /$ Xpedition $^{\circledR}$; Abbott Vascular). Details of the study protocol have been reported previously ${ }^{6}$. In brief, key angiographic inclusion criteria included: reference diameter $\geq 2.5 \mathrm{~mm}-\leq 3.75 \mathrm{~mm}$ and lesion length $\leq 24 \mathrm{~mm}$. Key angiographic exclusion criteria included: left main or ostial location; heavily calcified lesion and bifurcation lesion with side branch $\geq 2 \mathrm{~mm}$ in diameter. The sizes of the BVS available in the study were $2.5,3.0$, and $3.5 \mathrm{~mm}$ in diameter, and $8,12,18$, and $28 \mathrm{~mm}$ in length. Treatment with the same size matrix was required for patients assigned to the $\mathrm{CoCr}$ EES arm. A total of 28 MSCT sites with at least 64-slice scanners were preselected based on their willingness to participate in the substudy. Enrolment in the MSCT substudy was specified before randomisation. In the MSCT substudy, patients were scheduled to undergo CT angiography prior to invasive coronary angiography at 13 months. Standard CT acquisition techniques were used, which included using beta-blockers in patients with a fast heart rate and ensuring accurate tube voltage (100 to $120 \mathrm{kV})$ depending on patient size. Coronary angiography was performed using standard techniques by operators who were blinded to the MSCT results.

The primary endpoint of the substudy was assessability by MSCT. The institutional review board at each investigational site approved the trial protocol. All patients provided written informed consent.

\section{MSCT IMAGE ANALYSIS}

MSCT images were analysed at an independent core laboratory (Cardiocore Japan, Tokyo, Japan), blinded to the results of the coronary angiography. The image quality was evaluated by two observers. Images with distinct anatomic details and without noise or artefacts were rated as "excellent." Images with clear anatomic details, but with mild or moderate increase in noise and/or artefacts not affecting the diagnostic ability, were rated as "good." Images with a distinct increase in noise and/or artefacts affecting the diagnostic ability were rated as "poor." The "excellent" and "good" image qualities were classified as assessable to diagnose restenosis ${ }^{3}$. In case of disagreement, a third observer's opinion was taken.

The quantitative MSCT analysis was performed by a validated software (QAngio CT Research Edition 2.1; Medis medical imaging systems, Leiden, the Netherlands) ${ }^{7,8}$. Parameters such as minimal lumen diameter (MLD), lesion length, minimal lumen area were derived. The reference vessel diameter (RVD) was calculated as the average of the mean proximal and distal lumen diameters. The diameter stenosis (DS) was calculated as the reference minus the minimal lumen diameter as a percentage of the reference lumen diameter. Significant restenosis was defined as a diameter stenosis $\geq 50 \%$.

\section{QUANTITATIVE CORONARY ANGIOGRAPHY}

Quantitative coronary angiography (QCA) was performed at an angiographic core laboratory (Beth Israel Deaconess Medical Center, Boston, MA, USA), blinded to the MSCT results. The software used was QAngio XA 7.3 (Medis medical imaging systems). Binary restenosis was defined as a diameter stenosis $\geq 50 \%$.

\section{STATISTICAL ANALYSIS}

The full-analysis-set (FAS) population, defined as patients who received the assigned study device at the target lesion, was used on a per lesion basis for this MSCT substudy. For binary variables, counts and percentages were calculated, and the p-value based on Pearson's $\chi^{2}$ test was used when Cochran's rule was met ${ }^{9}$. Otherwise, Fisher's exact test was used. For continuous variables, means and standard deviations were calculated, and t-tests were performed. A Bland-Altman plot of the MLD was displayed to evaluate the agreement between two different instruments/ 
measurement techniques (MSCT and QCA). All statistical analyses were performed using SAS version 9.2 or higher (SAS Institute Inc., Cary, NC, USA).

\section{Results}

\section{PATIENT POPULATION}

Of the 400 patients enrolled in the ABSORB Japan trial, the study population consisted of 147 patients with 152 lesions assigned to the MSCT substudy (98 patients with 103 lesions in the BVS arm, and 49 patients with 49 lesions in the CoCr-EES arm) (Figure 1). In the BVS arm, one patient did not receive the assigned study device and was excluded from the FAS analysis. Of the FAS population, CT coronary angiography was performed in 84 BVS patients with 88 lesions $(87 \%)$ and in 42 CoCr-EES patients with 42 lesions (86\%). One BVS patient who underwent target lesion revascularisation with a metallic stent prior to 13-month follow-up was excluded, which resulted in an analysis population consisting of 83 patients with 87 lesions in the BVS arm and 42 patients with 42 lesions in the CoCr-EES arm. Baseline reference vessel diameter was significantly larger in the CoCr-EES arm compared to the BVS arm (Table 1). There were no significant differences in the other baseline patient and lesion characteristics between the two arms.

\section{QUALITATIVE MSCT DATA}

CT scanners from all major manufacturers were used (Table 2). Except for the more frequent use of Discovery CT750HD (GE Healthcare, Chicago, IL, USA) in the CoCr-EES arm, there were no differences in the types of scanners or parameters between the two arms.
The assessability of coronary stenosis by MSCT was significantly higher in the BVS arm than in the CoCr-EES arm $(94 \%$ versus $67 \%, p<0.0001$ ) (Table 3). The metal artefact caused by stent struts contributed $29 \%$ to the poor image quality in the $\mathrm{CoCr}$ EES arm. Typical non-assessable MSCT images are shown in Figure 2. In contrast, metal artefact caused by the edge markers of the BVS precluded the assessment in only $1.1 \%$ of the analysed lesions $(\mathrm{p}<0.0001)$. Representative non-assessable MSCT images due to metal artefact caused by the edge markers of the BVS are shown in Figure 3. Calcification, motion artefact and insufficient contrast in the lumen resulting in poor image quality were seen in similar frequencies in the BVS and CoCr-EES arms. Restenosis was not observed in the assessable segments either in the BVS arm or in the CoCr-EES arm.

In the CoCr-EES arm, the non-assessable image rate was higher in the $2.5 \mathrm{~mm}$ stents compared to the $3.0 / 3.5 \mathrm{~mm}$ stents $(75.0 \%$ versus $23.5 \%$, respectively, $\mathrm{p}=0.01$ ), whereas no difference was observed in the BVS arm between the $2.5 \mathrm{~mm}$ scaffolds and the $3.0 / 3.5 \mathrm{~mm}$ scaffolds $(5.6 \%$ versus $5.8 \%$, respectively, $\mathrm{p}=1.00)$ (Table 4). In the BVS group, the rate of non-assessable segments was $10.0 \%$ in 64-slice MSCT (one non-assessable segment in 10 segments), which is not statistically different from that in MSCT scanners greater than 64-slice (5.2\% [four non-assessable segments in 77 segments], $\mathrm{p}=0.47$ ). In the CoCr-EES group, the rate of non-assessable segments was $18.2 \%$ in 64-slice MSCT (two non-assessable segments in 11 segments), which is not different from that in MSCT scanners greater than 64-slice $(38.7 \%$ [12 non-assessable segments in 31 segments], $p=0.28$ ). There was a statistical difference in the rate of non-assessable segments among the scanner types in the BVS arm $(0 \%$ [0/52] in the one

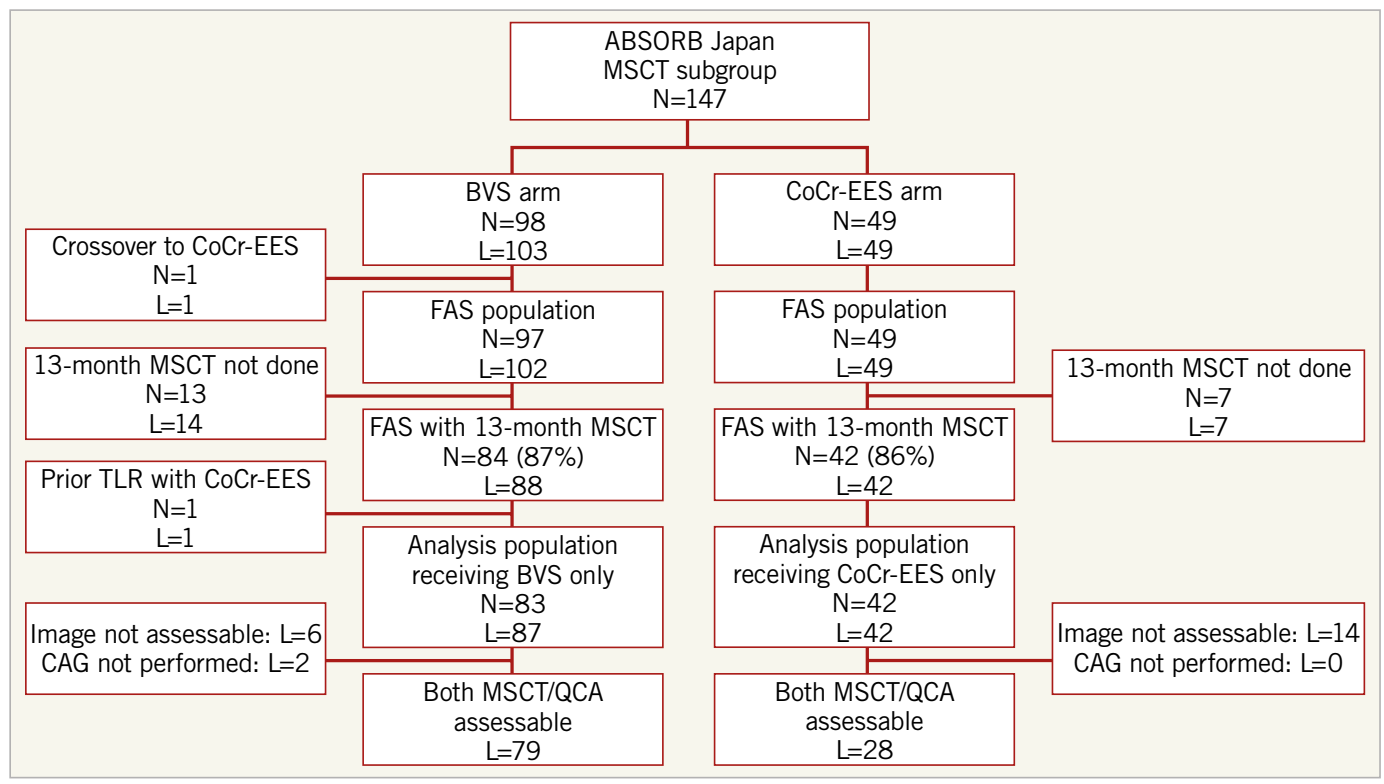

Figure 1. Patient flow chart. BVS: bioresorbable vascular scaffolds; CoCr-EES: cobalt-chromium everolimus-eluting stents; FAS: fullanalysis-set; L: number of lesions; MSCT: multislice computed tomography; N: number of patients; QCA: quantitative coronary angiography; TLR: target lesion revascularisation 
Table 1. Baseline characteristics.

\begin{tabular}{|c|c|c|c|c|}
\hline \multicolumn{2}{|l|}{ 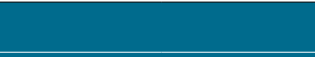 } & BVS & CoCr-EES & $p$-value \\
\hline \multicolumn{5}{|l|}{ Patients } \\
\hline \multicolumn{2}{|c|}{ Number of patients } & 97 & 49 & \\
\hline \multicolumn{2}{|l|}{ Age (years) } & $66.8 \pm 9.4$ & $68.3 \pm 10.2$ & 0.38 \\
\hline \multicolumn{2}{|l|}{ Male } & $73(75 \%)$ & $37(76 \%)$ & 0.97 \\
\hline \multicolumn{2}{|c|}{ Body mass index $\left(\mathrm{kg} / \mathrm{m}^{2}\right)$} & $24.3 \pm 2.9$ & $24.3 \pm 2.6$ & 0.96 \\
\hline \multicolumn{2}{|c|}{ eGFR <60 (mL/min) } & $31(32 \%)$ & $10(20 \%)$ & 0.14 \\
\hline \multicolumn{5}{|c|}{ Target lesions } \\
\hline \multicolumn{2}{|c|}{$\begin{array}{l}\text { Total number of target } \\
\text { lesions }\end{array}$} & 102 & 49 & \\
\hline \multicolumn{2}{|c|}{$\begin{array}{l}\text { Left anterior descending } \\
\text { coronary artery }\end{array}$} & $48(47 \%)$ & $27(55 \%)$ & 0.35 \\
\hline \multicolumn{2}{|c|}{$\begin{array}{l}\text { Left circumflex coronary } \\
\text { artery/ramus }\end{array}$} & $27(27 \%)$ & $11(22 \%)$ & 0.59 \\
\hline \multicolumn{2}{|c|}{ Right coronary artery } & $27(27 \%)$ & $11(22 \%)$ & 0.59 \\
\hline \multicolumn{2}{|c|}{$\begin{array}{l}\text { Calcification (moderate } \\
\text { or severe) }\end{array}$} & $29(28 \%)$ & $21(43 \%)$ & 0.08 \\
\hline \multicolumn{2}{|l|}{ Bifurcation } & $40(40 \%)$ & $25(51 \%)$ & 0.19 \\
\hline \multirow{4}{*}{$\begin{array}{l}\text { ACC/AHA } \\
\text { lesion } \\
\text { classifica- } \\
\text { tion }\end{array}$} & A & $3(2.9 \%)$ & $2(4.1 \%)$ & 0.66 \\
\hline & B1 & $21(21 \%)$ & $5(10 \%)$ & 0.11 \\
\hline & B2 & $59(58 \%)$ & $27(55 \%)$ & 0.75 \\
\hline & C & 19 (19\%) & $15(30.6 \%)$ & 0.10 \\
\hline
\end{tabular}

\section{Baseline QCA}

\begin{tabular}{|l|c|c|c|}
\hline Lesion length $(\mathrm{mm})$ & $13.51 \pm 4.92$ & $14.19 \pm 5.53$ & 0.47 \\
\hline $\begin{array}{l}\text { Reference vessel } \\
\text { diameter }(\mathrm{mm})\end{array}$ & $2.69 \pm 0.43$ & $2.89 \pm 0.47$ & 0.01 \\
\hline $\begin{array}{l}\text { Minimal lumen diameter } \\
(\mathrm{mm})\end{array}$ & $0.95 \pm 0.34$ & $1.02 \pm 0.37$ & 0.29 \\
\hline
\end{tabular}

\section{Device sizes used}

\begin{tabular}{|c|c|c|c|c|}
\hline $\begin{array}{l}\text { Diameter } \\
(\mathrm{mm})\end{array}$ & $\begin{array}{l}\text { Length } \\
(\mathrm{mm})\end{array}$ & & & \\
\hline \multirow[t]{3}{*}{3.5} & 12 & 5 (4.9\%) & 5 (10.2\%) & 0.29 \\
\hline & 18 & 25 (25\%) & $9(18 \%)$ & 0.40 \\
\hline & 28 & $10(9.8 \%)$ & $8(16 \%)$ & 0.25 \\
\hline \multicolumn{2}{|c|}{$3.5 \mathrm{~mm}$ Total } & 40 (39\%) & 22 (45\%) & 0.51 \\
\hline \multirow[t]{3}{*}{3.0} & 8 & $2(2.0 \%)$ & $2(4.1 \%)$ & 0.60 \\
\hline & 18 & $26(26 \%)$ & $12(25 \%)$ & 0.89 \\
\hline & 28 & $11(11 \%)$ & $3(6.1 \%)$ & 0.55 \\
\hline \multicolumn{2}{|c|}{$3.0 \mathrm{~mm}$ Total } & 39 (38\%) & $17(35 \%)$ & 0.67 \\
\hline \multirow[t]{3}{*}{2.5} & 8 & $1(1.0 \%)$ & $0(0.0 \%)$ & 1.00 \\
\hline & 18 & 17 (17\%) & $6(12 \%)$ & 0.48 \\
\hline & 28 & $5(4.9 \%)$ & $3(6.1 \%)$ & 0.71 \\
\hline \multicolumn{2}{|c|}{$2.5 \mathrm{~mm}$ Total } & 23 (23\%) & $9(18 \%)$ & 0.56 \\
\hline
\end{tabular}

There were no significant differences between groups. Data are expressed as number (percentage) or mean \pm SD. ACC/AHA: American College of Cardiology/American Heart Association; BVS: bioresorbable vascular scaffolds; CoCr-EES: cobalt-chromium everolimus-eluting stents; eGFR: estimated glomerular filtration rate; QCA: quantitative coronary angiography

rotation type, $14.3 \%$ [2/14] in the dual source type, $14.3 \%[3 / 21]$ in the helical scan type, $\mathrm{p}=0.02)$; however, no difference was observed in the CoCr-EES arm $(36 \%$ [9/25] in the one rotation
Table 2. Types of MSCT scanners and MSCT parameters.

\begin{tabular}{|c|c|c|c|}
\hline & $\begin{array}{c}\text { BVS (N=84) } \\
(L=88)\end{array}$ & $\begin{array}{c}\text { CoCr-EES } \\
(\mathrm{N}=42)(\mathrm{L}=42)\end{array}$ & $p$-value \\
\hline \multicolumn{4}{|l|}{ Type of MSCT scanner } \\
\hline Aquilion ONE & $53(60 \%)$ & $25(60 \%)$ & 1.00 \\
\hline $\begin{array}{l}\text { SOMATOM Definition } \\
\text { Flash }\end{array}$ & $11(13 \%)$ & $1(2.4 \%)$ & 0.10 \\
\hline Brilliance iCT & $3(3.4 \%)$ & $2(4.8 \%)$ & 0.66 \\
\hline SOMATOM Definition AS+ & $8(9.1 \%)$ & $2(4.8 \%)$ & 0.50 \\
\hline SOMATOM Definition & $3(3.4 \%)$ & $1(2.4 \%)$ & 1.00 \\
\hline SOMATOM Sensation 64 & $1(1.1 \%)$ & $0(0.0 \%)$ & 1.00 \\
\hline Aquilion 64 & $0(0.0 \%)$ & $1(2.4 \%)$ & 0.32 \\
\hline Brilliance 64 & $3(3.4 \%)$ & $1(2.4 \%)$ & 1.00 \\
\hline \multirow[t]{2}{*}{ Discovery CT750HD } & $6(6.8 \%)$ & $9(21.4 \%)$ & 0.02 \\
\hline & & & 0.48 \\
\hline \multicolumn{4}{|l|}{ MSCT parameters } \\
\hline Heart rate (bpm) & $54.8 \pm 7.9$ & $57.2 \pm 10.9$ & 0.22 \\
\hline Atrial fibrillation & $4(4.8 \%)$ & $3(7.1 \%)$ & 0.69 \\
\hline Scanning time (sec) & $3.7 \pm 3.7$ & $3.6 \pm 4.1$ & 0.90 \\
\hline \multicolumn{4}{|c|}{$\begin{array}{l}\text { Data are expressed as number (percentage) or mean } \pm \text { SD. } \\
\text { BVS: bioresorbable vascular scaffolds; CoCr-EES: cobalt-chromium } \\
\text { everolimus-eluting stents; L: number of lesions; MSCT: multislice } \\
\text { computed tomography; N: number of patients }\end{array}$} \\
\hline
\end{tabular}

Table 3. Qualitative MSCT data.

\begin{tabular}{|c|c|c|c|}
\hline & $\begin{array}{c}\text { BVS }(\mathrm{N}=83) \\
(\mathrm{L}=87)\end{array}$ & $\begin{array}{c}\text { CoCr-EES } \\
(\mathrm{N}=42)(\mathrm{L}=42)\end{array}$ & p-value \\
\hline \multicolumn{4}{|c|}{ Assessment of stenosis } \\
\hline $\begin{array}{l}\text { Able to assess } \\
\text { (assessable) }\end{array}$ & 82 (94\%) & $28(67 \%)$ & $<0.0001$ \\
\hline Excellent & $59(68 \%)$ & $10(24 \%)$ & $<0.0001$ \\
\hline Good & $23(26 \%)$ & $18(43 \%)$ & 0.06 \\
\hline Poor (not assessable) & $5(5.7 \%)$ & $14(33 \%)$ & $<0.0001$ \\
\hline \multicolumn{4}{|c|}{ Reasons for poor image quality } \\
\hline $\begin{array}{l}\text { Metal (stent/marker) } \\
\text { artefact }\end{array}$ & $1(1.1 \%)$ & $12(29 \%)$ & $<0.0001$ \\
\hline Calcification & $1(1.1 \%)$ & $2(4.8 \%)$ & 0.20 \\
\hline Motion artefact & $4(4.6 \%)$ & $1(2.4 \%)$ & 0.54 \\
\hline $\begin{array}{l}\text { Contrast media not } \\
\text { enough }\end{array}$ & $2(2.3 \%)$ & $2(4.8 \%)$ & 0.44 \\
\hline \multicolumn{4}{|c|}{$\begin{array}{l}\text { Data are expressed as number (percentage) based on lesion. The reasons } \\
\text { for poor image quality were not mutually exclusive. BVS: bioresorbable } \\
\text { vascular scaffolds; CoCr-EES: cobalt-chromium everolimus-eluting } \\
\text { stents; L: number of lesions; MSCT: multislice computed tomography; } \\
\mathrm{N} \text { : number of patients }\end{array}$} \\
\hline
\end{tabular}

type, $50 \%[1 / 2]$ in the dual source type, $26.7 \%$ [4/15] in the helical scan type, $\mathrm{p}=0.73$ ). The presence of moderate to severe calcified lesions did not affect the rate of non-assessable segments either in the BVS arm $(3.8 \%$ in the moderate to severe calcification vs. $6.6 \%$ in the none to mild calcification, $\mathrm{p}=1.00$ ) or in the $\mathrm{CoCr}-$ EES arm (36.8\% in the moderate to severe calcification vs. $30.4 \%$ in the none to mild calcification, $\mathrm{p}=0.66$ ). 


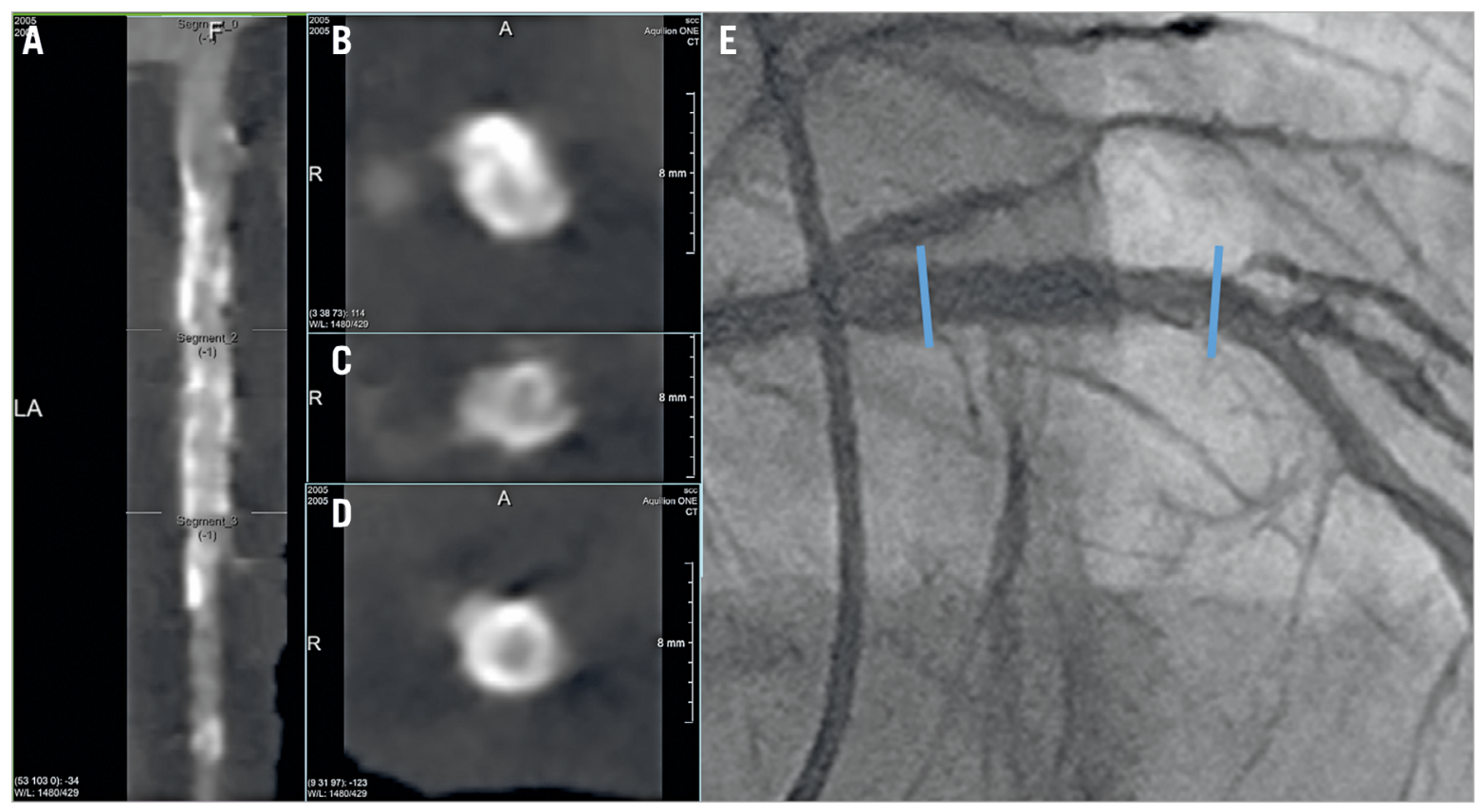

ved planar reformation (CPR) image from Figure 2. Non-assessable MSCT images in a patient with CoCr-EES implantation. A) Stretched curved planar reformation (CPR) image from
MSCT in a patient with a $3.5 \times 18 \mathrm{~mm}$ metallic CoCr-EES implantation in the proximal left anterior descending artery. B) Cross-sectional image of the proximal edge of the stent. C) Cross-sectional image of the mid portion of the stent. D) Cross-sectional image of the distal edge of the stent. E) Invasive coronary angiography performed at 13 months. The MSCT images were not assessable to determine the patency due to metal artefact, especially in the proximal half of the stent. Coronary angiography revealed no restenosis. The blue arrows indicate the edges of the stent. CoCr-EES: cobalt-chromium everolimus-eluting stent; MSCT: multislice computed tomography

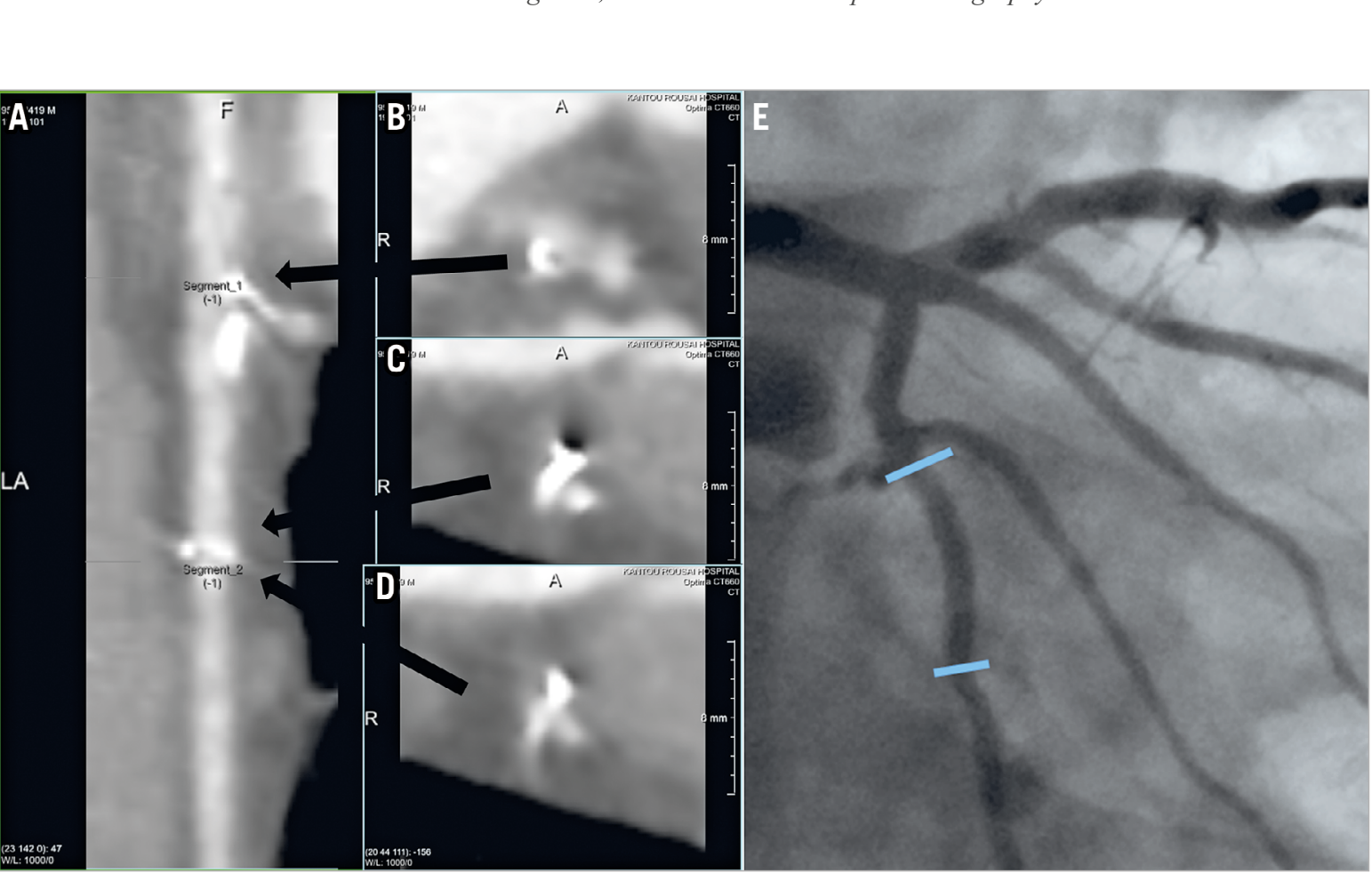

Figure 3. Non-assessable MSCT images in a patient with BVS implantation. A) Stretched curved planar reformation (CPR) image from MSCT in a patient with a $3.0 \times 18 \mathrm{~mm}$ BVS implantation in the mid portion of the left circumflex coronary artery. B) Cross-sectional image of the proximal edge of the scaffold. C) \& D) Cross-sectional images of the distal edge of the scaffold. E) Invasive coronary angiography performed at 13 months. The MSCT images were not assessable to determine the patency due to metal artefact, especially in the distal edge of the scaffold. Coronary angiography revealed no restenosis. The blue arrows indicate the edges of the scaffold. BVS: bioresorbable vascular scaffold; MSCT: multislice computed tomography 
Table 4. MSCT image quality according to the device diameter.

\begin{tabular}{|l|c|c|c|}
\hline \multicolumn{1}{|c|}{ Device diameter } & $\mathbf{3 . 0 / 3 . 5} \mathbf{~ m m}$ & $\mathbf{2 . 5} \mathbf{~ m m}$ & p-value \\
\hline BVS & L=69 & L=18 & \\
\hline Excellent & $68.1 \%$ & $66.7 \%$ & 0.97 \\
\hline Good & $26.1 \%$ & $27.8 \%$ & 1.00 \\
\hline Poor (not assessable) & $5.8 \%$ & $5.6 \%$ & 1.00 \\
\hline CoCr-EES & L=34 & L=8 & \\
\hline Excellent & $29.4 \%$ & $0.0 \%$ & 0.16 \\
\hline Good & $47.1 \%$ & $25.0 \%$ & 0.43 \\
\hline Poor (not assessable) & $23.5 \%$ & $75.0 \%$ & 0.01 \\
\hline $\begin{array}{l}|l| \\
\text { Data are expressed as number (percentage) based on lesion. } \\
\text { BVS: bioresorbable vascular scaffolds; CoCr-EES: cobalt-chromium } \\
\text { everolimus-eluting stents; L: number of lesions; MSCT: multislice } \\
\text { computed tomography }\end{array}$ \\
\hline
\end{tabular}

The time interval between MSCT and coronary angiography was $15.3 \pm 14.8$ days. In the ABSORB Japan trial, there were six cases of angiographic in-device binary restenosis observed at 13-month angiographic follow-up (four in the BVS arm, and two in the CoCr-EES arm), of which only one patient in the CoCrEES arm was assigned to the MSCT subgroup with non-assessable MSCT images. The angiographic core laboratory reported no angiographic restenosis in the segments assessable by MSCT. All the diagnoses made by the MSCT core laboratory in the assessable segments were in agreement with the diagnoses made by the angiographic core laboratory.

\section{QUANTITATIVE DATA}

Among the patients with assessable segments by MSCT, coronary angiography was not performed in two BVS patients (two lesions). As a result, paired quantitative MSCT and QCA data were available in 79 lesions in the BVS arm and in 28 lesions in the CoCr-EES arm for quantitative MSCT analysis (Figure 1). In the BVS arm, in-device MLD derived from MSCT $(2.30 \pm 0.44 \mathrm{~mm})$ was similar to that derived from QCA $(2.28 \pm 0.45 \mathrm{~mm})$. In the CoCr-EES arm, the in-device MLD by MSCT $(2.01 \pm 0.39 \mathrm{~mm})$ was smaller than that by QCA $(2.62 \pm 0.45 \mathrm{~mm})$. Bland-Altman analysis showed that MLD by MSCT was smaller than MLD by QCA with a difference of $0.61 \mathrm{~mm}$ in the CoCr-EES arm, while the difference was only $0.026 \mathrm{~mm}$ in the BVS arm (Figure 4A). Figure 5 shows an excellent image by MSCT in the CoCr-EES arm, which revealed no restenosis. The in-device MLD by MSCT (2.74 mm), however, was much smaller than that by QCA $(3.12 \mathrm{~mm})$. An excellent image by MSCT in the BVS arm is depicted in Figure 6, which shows no restenosis. The in-device MLD by MSCT $(1.79 \mathrm{~mm})$ was similar to that by QCA $(1.795 \mathrm{~mm})$. Bland-Altman analysis of the RVD (Figure 4B) showed that the difference between MSCT and QCA in the CoCr-EES arm $(0.07 \mathrm{~mm})$ was similar to that in the BVS arm $(-0.12 \mathrm{~mm})$. As a result, the difference in $\% \mathrm{DS}$ in the CoCr EES $(-18.7 \%)$ was greater than that in the BVS $(-2.5 \%)$ (Figure 4C).
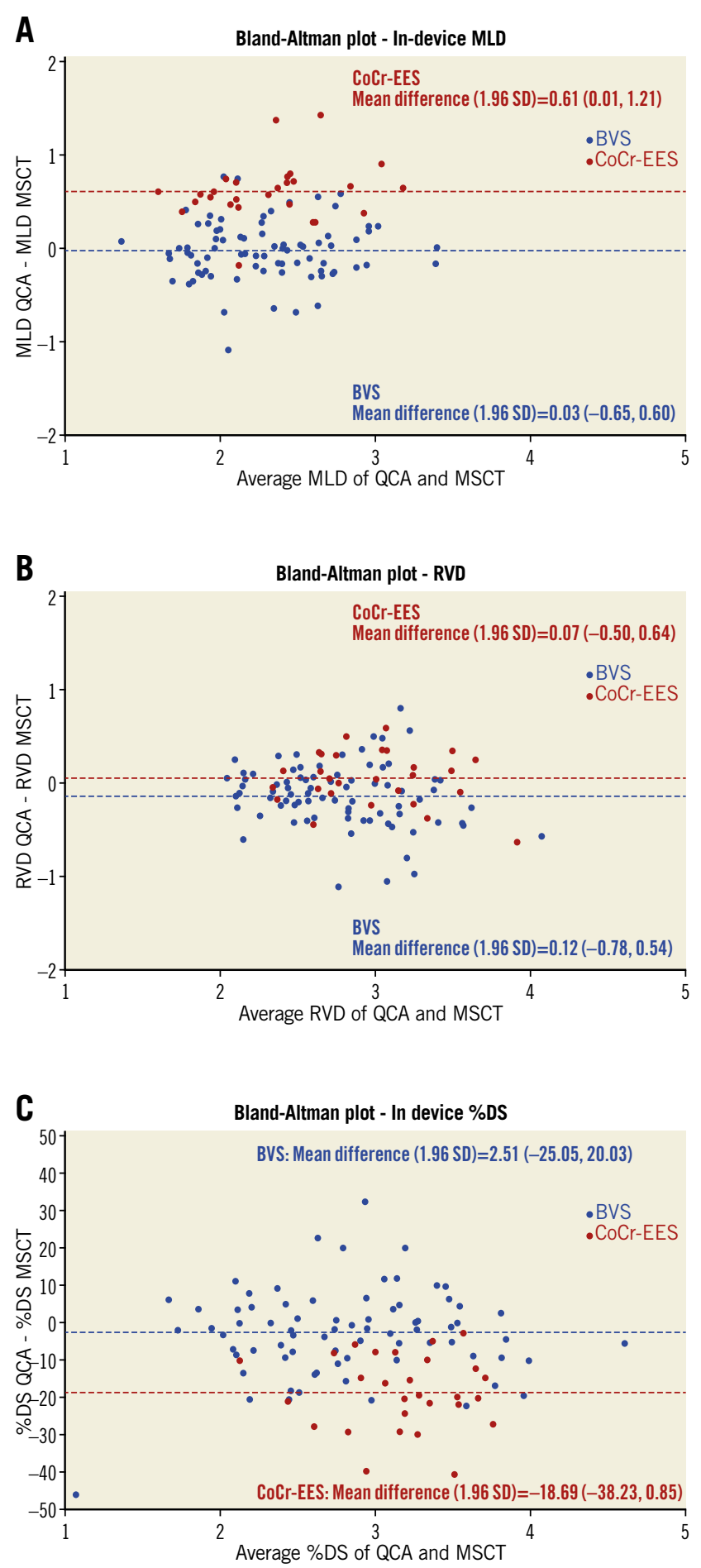

Figure 4. Comparison of QCA and MSCT parameters A) BlandAltman plot of the difference in the in-device minimal lumen diameter between QCA and MSCT. B) Bland-Altman plot of the difference in the reference vessel diameter between QCA and MSCT. C) BlandAltman plot of the difference in the in-device percent diameter stenosis between QCA and MSCT. Red and blue dots indicate the CoCr-EES and BVS arm, respectively. BVS: bioresorbable vascular scaffolds; CoCr-EES: cobalt-chromium everolimus-eluting stents; MLD: minimal lumen diameter; MSCT: multislice computed tomography; \%DS: percent diameter stenosis; QCA: quantitative coronary angiography; RVD: reference vessel diameter 


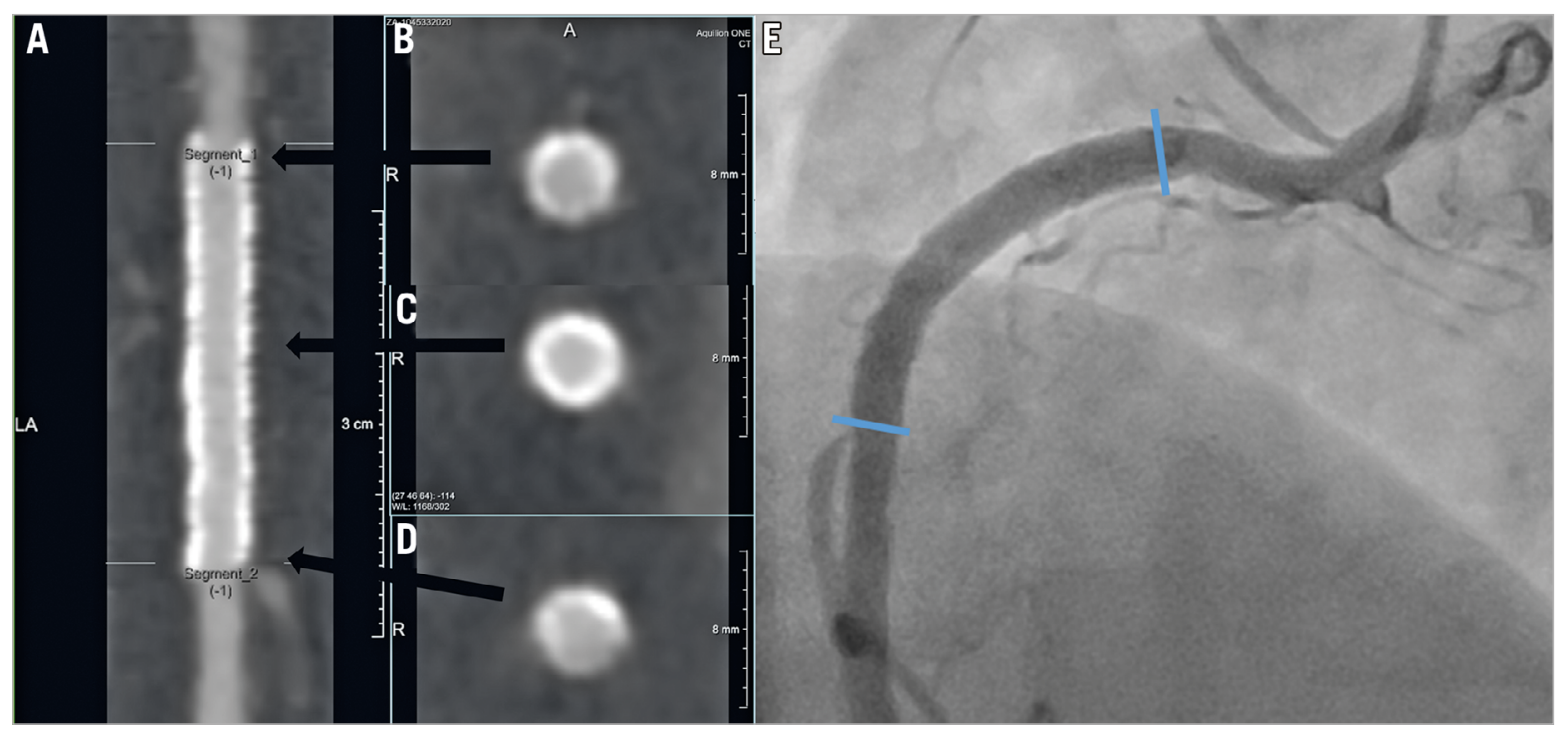

Figure 5. Assessable MSCT images in a patient with CoCr-EES implantation. A) Stretched curved planar reformation (CPR) image from MSCT in a patient with a $3.5 \times 28 \mathrm{~mm}$ metallic CoCr-EES implantation in the proximal right coronary artery. B) Cross-sectional image of the proximal edge of the stent. C) Cross-sectional image of the mid portion of the stent. D) Cross-sectional image of the distal edge of the stent. E) Invasive coronary angiography performed at 13 months. The blue arrows indicate the edges of the stent. Both MSCT and coronary angiography images revealed no restenosis. CoCr-EES: cobalt-chromium everolimus-eluting stent; MSCT: multislice computed tomography

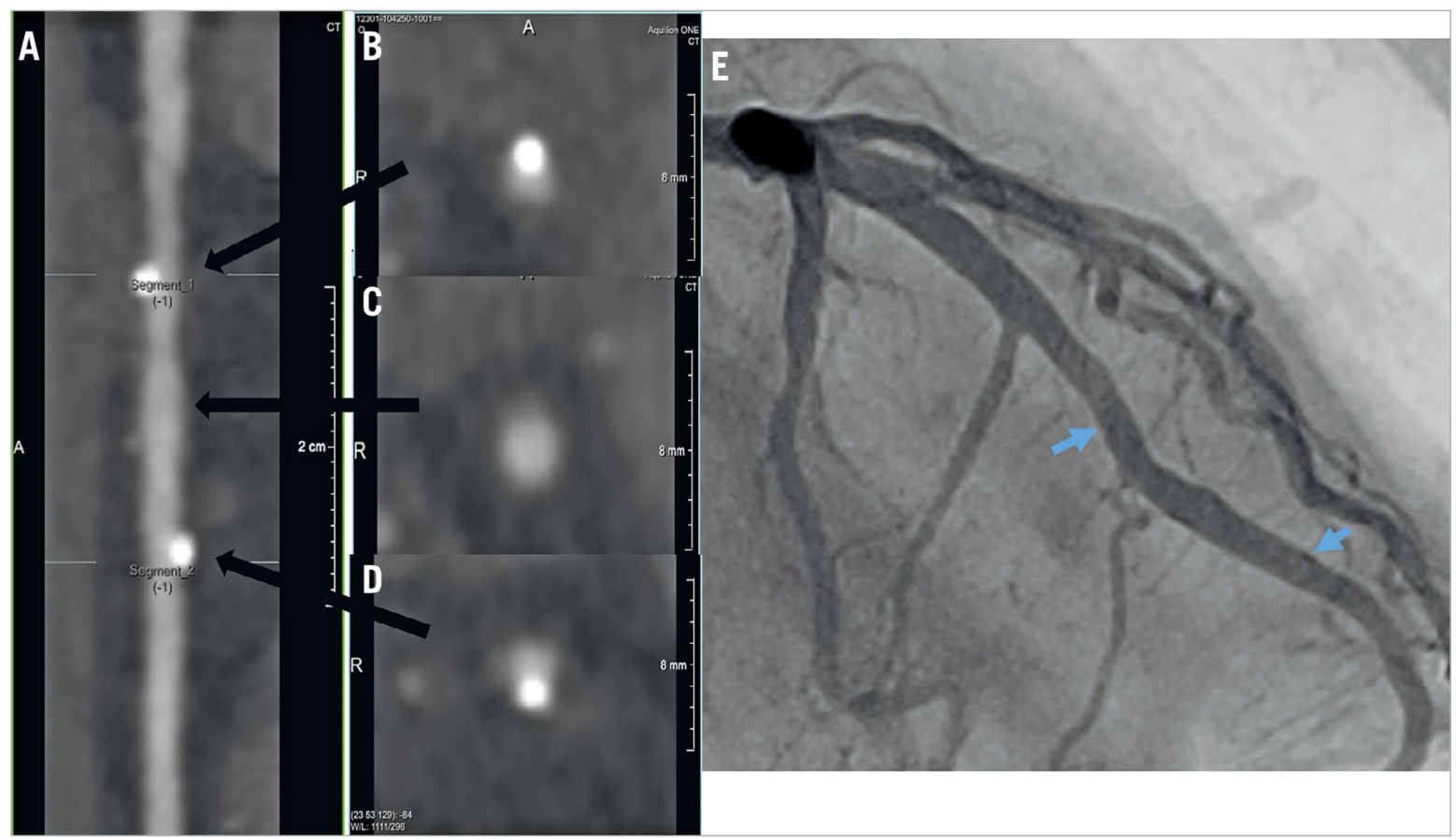

Figure 6. Assessable MSCT images in a patient with BVS implantation. A) Stretched curved planar reformation (CPR) image from MSCT in a patient with a $3.0 \times 18 \mathrm{~mm}$ BVS implantation in the mid portion of the left anterior descending coronary artery. B) Cross-sectional image of the proximal edge of the scaffold. C) Cross-sectional image of the mid portion of the scaffold. D) Cross-sectional image of the distal edge of the scaffold. E) Invasive coronary angiography performed at 13 months. The blue arrows indicate the edges of the scaffold. Both MSCT and coronary angiography images revealed no restenosis. BVS: bioresorbable vascular scaffold; MSCT: multislice computed tomography

\section{Discussion}

The key findings of this MSCT substudy are the following: 1) assessability of coronary stenosis by MSCT was better in the
BVS-treated lesions than in the CoCr-EES-treated lesions, mainly due to less blooming artefact caused by metal; 2) the device diameter had an influence on the assessability of coronary stenosis in 
the CoCr-EES-treated lesions, but not in the BVS-treated lesions; 3) the quantitative difference in the measurement of in-device MLD was $0.61 \mathrm{~mm}$ between MSCT and QCA in the CoCr-EES arm, but only a small difference $(0.026 \mathrm{~mm})$ was observed in the BVS arm.

The high diagnostic accuracy of MSCT to detect coronary de novo lesions has been demonstrated in prospective studies in comparison with coronary angiography ${ }^{10}$. However, there has been no prospective multicentre study with independent core laboratory analysis to investigate the diagnostic performance of MSCT to detect restenosis following coronary metallic stent implantation. The assessment of coronary stenosis in the stented segment is more difficult than in the native coronary artery, mainly due to blooming artefacts caused by metal. In fact, a relatively low MSCT assessability ranging from $52 \%$ to $92 \%{ }^{1-3}$ has been reported for stented lesions in previous studies. Therefore, the appropriate use criteria for cardiac computed tomography ${ }^{11}$ assume a cautious attitude to the assessment of stented segments. Only a prior left main coronary stent with a stent diameter $\geq 3 \mathrm{~mm}$ is rated as appropriate. The other segment with a stent diameter $\geq 3 \mathrm{~mm}$ is classified as uncertain. Further, a stent diameter $<3 \mathrm{~mm}$ is classified as inappropriate. The assessability of the CoCr-EES-treated lesions in the present study was $66.7 \%$, which was within the range of those reported in previous studies ${ }^{1-3}$. The main reason for the non-assessable images was stent artefact in $29 \%$ of the lesions. Our finding that poor image quality (not assessable) was more prevalent in the segments treated with a $2.5 \mathrm{~mm}$ stent compared to those treated with a $3.0 / 3.5 \mathrm{~mm}$ stent supports the appropriate use criteria.

In contrast, the assessability of coronary stenosis in the BVS arm was $94.3 \%$, which is significantly higher compared to the CoCr-EES arm. The edge marker artefact precluded analysis in only $1.1 \%$ of the lesions. Given the fact that the BVS is not completely resorbed until approximately three years and the MSCT was performed at 13 months in the present study, the MSCT assessment is not confounded by the presence of a scaffold during its process of absorption. The only possibility to induce metal artefact is the platinum markers in the scaffold edges. This could be a reason for the lack of difference in the image quality between the segments treated with a $3.0 / 3.5 \mathrm{~mm}$ scaffold and those treated with a $2.5 \mathrm{~mm}$ scaffold.

In terms of quantitative analysis, MSCT systematically underestimated in-device MLD compared to QCA in the CoCr-EES arm. The lumen contours in the MSCT images might have been delineated more inside than those in the QCA images due to blooming artefacts of metallic struts. In contrast, a good agreement for the in-device MLD between MSCT and QCA was observed in the BVS group with a difference of only $0.026 \mathrm{~mm}$. Thus, the BVS would be much more suitable for quantitative MSCT analysis as compared with the metallic stent. There was a good agreement for the RVD in both the BVS and CoCr-EES groups. Metallic struts did not affect the quantitative MSCT analysis in reference segments.

\section{Limitations}

The MSCT substudy was not powered to detect the significant difference of the assessability between the two arms. The study was performed in a preselected population, comprising 28 participating sites using nine types of MSCT, ranging from 64 to 320 slices. Although the standard MSCT acquisition technique was used, the variety of CT scanners might have influenced the results. The allocation of study device could not be blinded by the core lab analysts due to vastly different CTA imaging profiles. In addition, heavy calcification proximal to or within the target lesion was one of the angiographic exclusion criteria per the ABSORB Japan study protocol and hence the results could not be extrapolated for heavily calcified lesions. Lastly, reference vessel diameter at baseline was significantly larger in the CoCr-EES arm; however, considering the fact that a larger vessel is advantageous for MSCT assessment, the difference had a low impact on the conclusion that the feasibility of MSCT assessment in BVS was greater than in CoCr-EES.

\section{Conclusions}

In this pre-specified randomised MSCT substudy, the non-invasive MSCT assessment of BVS-treated lesions is more feasible than that of metallic stent-treated lesions. However, the present study did not include restenosis; thus, it remains uncertain whether MSCT could detect BVS restenosis.

\section{Impact on daily practice}

The MSCT substudy of the ABSORB Japan trial is the first prospective randomised comparison of the diagnostic capability of MSCT between two coronary devices. The assessability of BVS by MSCT was superior to that of metallic stents. To avoid unnecessary invasive coronary angiography, the feasibility of MSCT assessment following BVS implantation would benefit patients.

\section{Guest Editor}

This paper was guest edited by Daniele Andreini, MD, PhD, FESC, FSCCT; Cardiovascular CT Unit, Centro Cardiologico Monzino, IRCCS, Milan, and Department of Clinical Sciences and Community Health, Cardiovascular Section, University of Milan, Milan, Italy.

\section{Acknowledgements}

The authors thank Dr Satoru Kishi, Dr Masahiko Asami, Dr Nahoko Kato, core laboratory staff, and investigators of the study for their valuable contributions.

\section{Funding}

This study was sponsored by Abbott Vascular. The sponsor was involved in study design, data collection, data analysis, data interpretation, and writing of this report.

\section{Conflict of interest statement}

$\mathrm{K}$. Tanabe is a member of the Advisory Board of Abbott Vascular Japan, and receives honoraria for lectures from Abbott Vascular Japan and Toshiba. J. Popma is a member of the Advisory Board of 
Abbott Vascular. K. Kozuma is a member of the Advisory Board of Abbott Vascular Japan. P.W. Serruys is a member of the Advisory Board of Abbott Vascular. Y. Onuma is a member of the Advisory Board of Abbott Vascular Japan. S. Ying is an employee of Abbott Vascular. H. Kusano is an employee of Abbott Vascular. G. Stone is a member of the Advisory Board of Abbott Vascular and is a consultant to Reva Corp. T. Kimura is a member of the Advisory Board of Abbott Vascular. The other authors have no conflicts of interest to declare. The Guest Editor has no conflicts of interest to declare.

\section{References}

1. Carrabba N, Schuijf JD, de Graaf FR, Parodi G, Maffei E, Valenti R, Palumbo A, Weustink AC, Mollet NR, Accetta G, Cademartiri F, Antoniucci D, Bax JJ. Diagnostic accuracy of 64-slice computed tomography coronary angiography for the detection of in-stent restenosis: a meta-analysis. J Nucl Cardiol. 2010;17: $470-8$.

2. Sun Z, Davidson R, Lin CH. Multi-detector row CT angiography in the assessment of coronary in-stent restenosis: a systematic review. Eur J Radiol. 2009;69:489-95.

3. Hang CL, Lee YW, Guo GB, Youssef AA, Yip HK, Liu CF, Chua S, Chang HW, Cheng YF, Chen SM. Evaluation of coronary artery stent patency by using 64-slice multi-detector computed tomography and conventional coronary angiography: a comparison with intravascular ultrasonography. Int J Cardiol. 2013;166:90-5.

4. Asami M, Aoki J, Serruys PW, Abizaid A, Saito S, Onuma Y, Kimura T, Simonton CA, Tanabe K. Feasibility of 320-row multidetector computed tomography angiography to assess bioabsorbable everolimus-eluting vascular scaffolds. Cardiovasc Interv Ther. 2016;31:96-100.

5. Onuma Y, Dudek D, Thuesen L, Webster M, Nieman K, Garcia-Garcia HM, Ormiston JA, Serruys PW. Five-year clinical and functional multislice computed tomography angiographic results after coronary implantation of the fully resorbable polymeric everolimus-eluting scaffold in patients with de novo coronary artery disease: the ABSORB cohort A trial. JACC Cardiovasc Interv. 2013;6:999-1009.

6. Kimura T, Kozuma K, Tanabe K, Nakamura S, Yamane M, Muramatsu T, Saito S, Yajima J, Hagiwara N, Mitsudo K, Popma JJ, Serruys PW, Onuma Y, Ying S, Cao S, Staehr P, Cheong WF, Kusano H, Stone GW; ABSORB Japan Investigators. A randomized trial evaluating everolimus-eluting Absorb bioresorbable scaffolds vs. everolimus-eluting metallic stents in patients with coronary artery disease: ABSORB Japan. Eur Heart J. 2015;36:3332-42.

7. Boogers MJ, Schuijf JD, Kitslaar PH, van Werkhoven JM, de Graaf FR, Boersma E, van Velzen JE, Dijkstra J, Adame IM,
Kroft LJ, de Roos A, Schreur JH, Heijenbrok MW, Jukema JW, Reiber JH, Bax JJ. Automated quantification of stenosis severity on 64-slice CT: a comparison with quantitative coronary angiography. JACC Cardiovasc Imaging. 2010;3:699-709.

8. de Graaf MA, El-Naggar HM, Boogers MJ, Veltman CE, Broersen A, Kitslaar PH, Dijkstra J, Kroft LJ, Al Younis I, Reiber JH, Bax JJ, Delgado V, Scholte AJ. Automated quantitative coronary computed tomography correlates of myocardial ischaemia on gated myocardial perfusion SPECT. Eur J Nucl Med Mol Imaging. 2013;40:1171-80.

9. Cochran WG. Statistical problems of the Kinsey report on Sexual behavior in the human male. A report of the American Statistical Association, Committee to Advise the National Research Council, Committee for Research in Problems of Sex. Washington: American Statistical Association; 1954.

10. Rochitte CE, George RT, Chen MY, Arbab-Zadeh A, Dewey M, Miller JM, Niinuma H, Yoshioka K, Kitagawa K, Nakamori S, Laham R, Vavere AL, Cerci RJ, Mehra VC, Nomura C, Kofoed KF, Jinzaki M, Kuribayashi S, de Roos A, Laule M, Tan SY, Hoe J, Paul N, Rybicki FJ, Brinker JA, Arai AE, Cox C, Clouse ME, Di Carli MF, Lima JA. Computed tomography angiography and perfusion to assess coronary artery stenosis causing perfusion defects by single photon emission computed tomography: the CORE320 study. Eur Heart J. 2014;35:1120-30.

11. Taylor AJ, Cerqueira M, Hodgson JM, Mark D, Min J, O'Gara P, Rubin GD; American College of Cardiology Foundation Appropriate Use Criteria Task Force; Society of Cardiovascular Computed Tomography; American College of Radiology; American Heart Association; American Society of Echocardiography; American Society of Nuclear Cardiology; North American Society for Cardiovascular Imaging; Society for Cardiovascular Angiography and Interventions; Society for Cardiovascular Magnetic Resonance, Kramer CM, Berman D, Brown A, Chaudhry FA, Cury RC, Desai MY, Einstein AJ, Gomes AS, Harrington R, Hoffmann U, Khare R, Lesser J, McGann C, Rosenberg A, Schwartz R, Shelton M, Smetana GW, Smith SC Jr. ACCF/SCCT/ACR/AHA/ASE/ASNC/NASCI/SCAI/SCMR 2010 appropriate use criteria for cardiac computed tomography. A report of the American College of Cardiology Foundation Appropriate Use Criteria Task Force, the Society of Cardiovascular Computed Tomography, the American College of Radiology, the American Heart Association, the American Society of Echocardiography, the American Society of Nuclear Cardiology, the North American Society for Cardiovascular Imaging, the Society for Cardiovascular Angiography and Interventions, and the Society for Cardiovascular Magnetic Resonance. J Am Coll Cardiol. 2010;56:1864-94. 